\title{
非線形モデル適合制御系設計と操舵系への応用*
}

\author{
内門茂*1, 長 保 浩*2, 小林 伸 明*3 \\ 金井 喜美雄 ${ }^{* 4}$, 田 中 幹 也*5
}

\section{Synthesis of Nonlinear Model Matching Control System and Its Application to Flight System}

\author{
Shigeru UCHIKADO, Yasuhiro OSA, Nobuaki KOBAYASHI, \\ Kimio KANAI and Kanya TANAKA
}

\begin{abstract}
The proposed control method is based on Hirschorn's Algorithm extended with Silverman's structure algorithm, and facilitates easy determination of the control law using the relationship, between the output and the input, which is obtained by differentiating the output. This method is the extension of the linear model matching control system for which the control law was proposed by Wolovich. The proposed control system is applied to a flight control system (for example, pitch angle, vertical velocity and $\mathrm{C}^{*}$ control system) and numerical simulations are shown to investigate the feasibility of the proposed approach.
\end{abstract}

Key Words : Optimal Control, Analog Control, Comfort in Riding, Aircraft, Nonlinear Control, Model Matching

\section{1. まえがき}

線形システムに対するモデル適合制御システムは 種々提案されているが, 非線形システムに対しては, ほとんど研究されていないのが現状である(1).

最近, 制御システムの作動環境や作動領域が拡大す る, 一方, ユーザの制御性能に対する仕様要求も厳し いものになっている(2). 航空機分野では, その高速化 および飛行領域の拡大など高性能化が著しく, 特に, 米国において研究開発中である TVC 形の航空機など に見られるように高迎え角領域で飛行する航空機が増 大する傾向にある(2) (4).このようなシステムは, 非線 形であり，従来の線形モデル適合制御則で制御するこ とは一般に不可能である。また，近年の計算機の高性 能化・高精度化・軽量小形化は，このような厳しい制 御要求を満足する複雑な制御システムの設計を可能に している(2).

* 原稿受付 1996 年: 6 月 21 日。

*1 東宗電機大学（更350-03 埼玉県比企郡鳩山町石坂）.

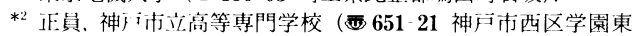
町 8-3).

*3 金沢1.業大学 (更921 不川県不门郡野々市町 7-1).

*4 防衛大学校（更239 横須賀市起水 1-10).

*5 䜣負, 愛媛大学（严790 松山这文京町 3).
本論文では, 非線形モデル適合制御システムの一設 計法を提案し, 航空機の操舵システムへの応用を検討 する.

まず, 非線形システムに対し, Silverman の Structure Algorithm(5) を拡張した Hirschornのアルゴリ ズム(6)(7) を基礎とした動的モデル適合制御システムを 導出する.この方式の特徵は, 出力の微分操作により, 入力信号の出力への影響度を求めることによって容易 に制御則を決定することが可能な点にある，また，こ の手法は, 結果として, Wolovichの提案したインタ ラクタ・マトリックス ${ }^{(8)}$ を出力に左から操作して制 御則を求める線形モデル適合制御方式の拡張である.

次に, 提案した制御システムを小形高速機 $\mathrm{CCV}$ の 操舵システムへ適用する。ここでは, 航空機の運動モ デルを導出し，ピッチ角制御システム，上下速度制御 システム, $\mathrm{C}^{*}$ 制御システムを設計する。この制御シ ステムの有効性を検討するために, 計算機シミュレー ションを実行する，特に, シミュレーションでは, 提 案した非線形と通常の線形モデル適合制御システムの 両方を実行して比較検討し，良好な結果を得た。

\section{2. 問題の記述}

制御対象として, 次の非線形システム (システム $\Sigma$ ) 
を考える。

$$
\begin{aligned}
& \dot{x}(t)=F(x)+B(x) u(t), x(0)=x_{0} \\
& y(t)=C x
\end{aligned}
$$

ただし $, x(t) \in R^{n}, y(t) \in R^{p}, u(t) \in R^{p}$ は状態, 入力, 出力を表すべクトルであり, この逆システムは安定 ${ }^{(6)}$ であると仮定する。 $F(x), B(x)$ は，状態に関する実 関数であり, $R^{n}$ の適当な開領域 $R \in R^{n}$ で解析的(十 分連続微分可能)であるとする. また, $x_{0} \in R$ および 区分的連続入力 $u$ に対し, 上記の系は $R$ 内で一意解 をもつものとする.さらに，

$$
\begin{aligned}
& F(x)=\left[f_{1}(x), f_{2}(x), \cdots, f_{n}(x)\right]^{T} \\
& f_{i}(x): R^{n} \rightarrow R \\
& B(x)=\left[b_{1}(x), b_{2}(x), \cdots, b_{n}(x)\right]^{T} \\
& b_{i}^{T}(x): R^{p} \rightarrow R \\
& C=\left[C_{1}, C_{2}, \cdots, C_{p}\right]^{T} \in R^{p \times n} \\
& x(t)=\left[x_{1}(t), x_{2}(t), \cdots, x_{n}(t)\right]^{T} \\
& y(t)=\left[y_{1}(t), y_{2}(t), \cdots, y_{p}(t)\right]^{T} \\
& u(t)=\left[u_{1}(t), u_{2}(t), \cdots, u_{p}(t)\right]^{T}
\end{aligned}
$$

である。

設計者が任意に設定する規範モデル(規範システム $\left.\Sigma_{M}\right)$ として次式を考える.

$$
\begin{aligned}
& \dot{X}_{M}(t)=A_{M} X_{M}(t)+B_{M} u_{M}(t) \\
& y_{M}(t)=C_{M} X_{M}(t) \cdots \cdots \cdots \cdots \cdots
\end{aligned}
$$

ここで, 規範状態 $X_{M}(t) \in R^{m}$ で有界な規範入力 $u_{M}(t) \in R^{p}$, 有界な規範出力 $y_{M}(t) \in R^{p}$ である.ま た,

$$
\begin{aligned}
& x_{M}(t)=\left[x_{M 1}(t), x_{M 2}(t), \cdots, x_{M m}(t)\right]^{T} \\
& y_{M}(t)=\left[y_{M 1}(t), y_{M 2}(t), \cdots, y_{M p}(t)\right]^{T} \\
& u_{M}(t)=\left[u_{M 1}(t), u_{M 2}(t), \cdots, u_{M p}(t)\right]^{T} \\
& C_{M}=\left[C_{M 1}, C_{M 2}, \cdots, C_{M p}\right]^{T}
\end{aligned}
$$

本研究の目的は, 状態ベクトル非線形システムの出 力 $y(t)$ を規範モデルの出力 $y_{M}(t)$ にモデル適合させ るモデル適合制御システムを設計することである.

ただし，ここで考えるモデル適合は次のように定義 する.

\section{（定義）}

システム $\Sigma$ および規範モデル $\Sigma_{M}$ において

$$
x_{0}=0, \quad x_{M 0}=0, \quad F\left(x_{0}\right)=0, \quad B\left(x_{0}\right)=0
$$

に対し

$$
y_{M}(t)=y(t) \text { for } t \geqq 0
$$

が成立するとき，システム $\Sigma$ は規範モデル $\Sigma_{M}$ にモデ ル適合するという.

\section{3. モデル適合制御系の構成}

本章では, システム $\Sigma$ および規範モデル $\Sigma_{M} に$ 対 し, Silvermanの Structure Algorithm ${ }^{(5)}$ を拡張した
Hirschornのアルゴリズム(6) を基礎とした動的モデル 適合制御系を導出する.

システム $\Sigma$ および規範モデル $\Sigma_{M} に$ 対して, 次のよ うな出力の微分操作を行う.

(ステップ 1)

出力 $y_{1}(t)$ の時間微分を考え, 式 (1)〜 (4)の両辺 に左から $\left(s+g_{0}\right)$ を掛けると,

$$
\begin{aligned}
& \left(s+g_{0}\right) y_{1}(t)=\left[C_{1} F(x)+g_{0} C_{1} x(t)\right] \\
& \quad+C_{1} B(x) u(t) \\
& \left(s+g_{0}\right) y_{M 1}(t)=\left[C_{M 1} A_{M} x_{M}(t)+g_{0} C_{M 1} x_{M}(t)\right] \\
& \quad+C_{M_{1}} B_{M} u_{M}(t)
\end{aligned}
$$

となる.ここで, $g_{0}>0, s=d / d_{t}$ である.

次に,この式を形式的に,

$$
\begin{aligned}
& \left(s+g_{0}\right)^{f_{11}} y_{1}(t)=C_{a 11}(x)+D_{a 11}(x) u(t) \\
& \left(s+g_{0}\right)^{f_{11}} y_{M 1}(t)=C_{a M 11}(x) x_{M}+D_{a M 11}(x) u_{M}(t)
\end{aligned}
$$

とおく.つまり, サフィクスの 11 の前の 1 は出力の 1 番めを, また, 後者の 1 は $\left(s+g_{0}\right)^{1}$ のべき乗の 1 を 表す。また,一般に, $C_{a 11}(x), D_{a 11}(x), C_{a M 11}(x)$ や $D_{a M 11}(x)$ は $x$ に関する実関数である.

上式において, $D_{a 11}(x) \neq 0$ ならば $f_{11}$ と $C_{a 11}$ および $D_{a 11}$ を $f_{1}$ と $C_{a 1}$ および $D_{a 1}$ と置き換えて次のステッ プへ進む.もし, $D_{a 11}(x)=0$ ならば,さらに微分を続 けると，

$$
\begin{aligned}
& \left(s+g_{0}\right)^{f_{1 j}} y_{1}(t)=C_{a 1 j}(x)+D_{a 1 j}(x) u(t) \\
& \left(s+g_{0}\right)^{f_{1 j}} y_{M 1}(t)=C_{a M 1 j}(x) x_{M}+D_{a M 1 j}(x) u_{M}(t)
\end{aligned}
$$

が得られる。ここで, $D_{a 1 j}(x) \neq 0$ である.ただし、こ の式を満足する $j$ は存在すると仮定する.上式におい て, 前と同様に $f$ と $C_{a}$ および $D_{a}$ のサフィクス $1 j$ を 1 と置き換えて次のステップへ進む.

(ステップ 2 )

出力 $y_{2}(t)$ についてステップ 1 と同様の操作を行う と,

$$
\begin{aligned}
& \left(s+g_{0}\right)^{f_{2 j}} y_{2}(t)=C_{a 2 j}(x)+D_{a 2 j}(x) u(t) \\
& \left(s+g_{0}\right)^{f_{2 j}} y_{M 2}(t)=C_{a M 2 j}(x) x_{M}+D_{a M 2 j}(x) u_{M}(t)
\end{aligned}
$$

が得られる.

(ステップ 3 )

$D_{a 2 j}(x) \neq \alpha_{21}(x) D_{a 1}(x) ;\left[\alpha_{21}(x) \neq 0\right]$ ならば, サフ イクス $2 j$ を 2 置き換えて $y_{3}(t)$ についてステップ 2 以降を実行する。ただし， $\alpha_{21}(x)$ は $x$ に関する実関 数である。

もし, $D_{a 2 j}(x)=\alpha_{21}(x) D_{a 1}(x)$ ならば, 新しい出力

$$
\begin{aligned}
& -\alpha_{21}(x)\left(s+g_{0}\right)^{f_{1}} y_{1}(t)+\left(s+g_{0}\right)^{f_{2 j}} y_{2}(t) \\
& -\alpha_{21}(x)\left(s+g_{0}\right)^{f_{1}} y_{M 1}(t)+\left(s+g_{0}\right)^{f_{2 j}} y_{M 2}(t)
\end{aligned}
$$

について, ステップ 2 以降を行う.

(ステップ 4 )

以上の操作を $y_{p}(t)$ および $y_{M p}(t)$ まで繰返すと, 


$$
\begin{aligned}
& N_{a}(s, x) y(t)=C_{a}(x)+D_{a}(x) u(t) \\
& N_{a}(s, x) y_{M}(t)=C_{a M}(x) x_{M}(t) \\
& +D_{a M}(x) u_{M}(t) \text {. }
\end{aligned}
$$

が得られる.ここで, $N_{a}(s, x)$ は対角要素が $\left(s+g_{0}\right)^{f_{i}}$ の下三角行列であり， $C_{a}(x)$ および $D_{a}(x)$ はそれぞ れ,

$$
\begin{aligned}
& C_{a}(x)=\left[C_{a 1}(x), C_{a 2}(x), \cdots, C_{a p}(x)\right]^{T} \\
& D_{a}(x)=\left[D_{a 1}(x), D_{a 2}(x), \cdots, D_{a p}(x)\right]^{T} \\
& C_{a M}(x)=\left[C_{a M 1}(x), C_{a M 2}(x), \cdots, C_{a M p}(x)\right]^{T} \\
& D_{a M}(x)=\left[D_{a M 1}(x), D_{a M 2}(x), \cdots, D_{a M p}(x)\right]^{T}
\end{aligned}
$$

である。なお, $N_{a}(s, x)$ が下三角行列になることは, $y_{j}(t)$ と $u(t)$ の関係を $y_{1}(t) y_{2}(t) \cdots y_{j}(t)$ の微分值を用 いて求めるステップ 3 の操作から明らかである.

上式の関係を用いると次の定理が得られる. 〈定理〉

次の条件

$$
\operatorname{rank}\left(D_{a}(x)\right)=p \text { for } x(t) \in R
$$

が満足されるならば,

$$
\begin{aligned}
& u(t)=D_{a}^{-1}(x)\left[-C_{a}(x)+C_{a M}(x) x_{M}\right. \\
& \left.+D_{a M}(x) u_{M}(t)\right]
\end{aligned}
$$

なる制御則によって, システム $\Sigma$ は規範モデル $\Sigma_{M} に$ モデル適合可能である.

(証明)

出力誤差 $e(t)$ を

$$
e(t)=y_{M}(t)-y(t)
$$

とすると, 式(5)〜(8)より

$$
\mathrm{Na}(s, x) e(t)=0
$$

が得られる.ここで, $N_{a}(s, x)$ の構造, 特に安定多項 式をもつ対角要素に着目すると, $x(0)=0, x_{M}(0)=0$, $F\left(x_{0}\right)=0, B\left(x_{0}\right)=0$ に対して,

$$
y(t)=y_{M}(t), \text { for } t \geqq 0 \cdots
$$

となり，モデル適合が達成される。なお，式（9)の関 係より，任意の初期值に対して,

$$
y(t) \rightarrow y_{M}(t) \text { for } t \rightarrow \infty
$$

が得られる。

$$
\text { (コメント) }
$$

本方式は, 結果として, $N_{a}(s, x)$ をシステムのイン タラクタマトリックスと置換すると, Wolovich の線 形モデル適合制御システムの拡張であることがわか $ろ^{(8)}$.

\section{4. 航空機の操舵システムへの応用}

$4 \cdot 1$ 航空機の運動モデル 制御対象として, 小 形高速機 CCV を考える．昇降舵角を入力とする縦の 非線形運動方程式は，次のように表される。

$$
\dot{V}(t)=(\rho S / 2 m) V_{T}^{2}\left(C_{x}+C_{x d h} \Delta_{h}(t)\right)
$$

$$
\begin{aligned}
& -g \sin \Theta(t)-W(t) Q(t)+T / m \\
& \dot{W}(t)=(\rho S / 2 m) V_{T}^{2}\left(C_{z}+C_{z d h} \Delta_{h}(t)\right) \\
& +g \cos \Theta(t)+V(t) Q(t) \\
& \dot{Q}(t)=\left(\rho S \bar{C} / 2 I_{y}\right) V_{T}^{2}\left(C_{m}+C_{m d h} \Delta_{n}(t)\right) \\
& +\left(\rho S \bar{C}^{2} / 4 I_{y}\right) V_{T} C_{m q} Q(t) \\
& \dot{\Theta}(t)=Q(t)
\end{aligned}
$$

ここで,

$V(t)$ : 前後速度 $\mathrm{m} / \mathrm{s}$

$W(t)$ : 上下速度 $\mathrm{m} / \mathrm{s}$

$Q(t)$ : ピッチ角速度 $\mathrm{rad} / \mathrm{s}$

$\Theta(t)$ : ピッチ角 $\mathrm{rad}$

$\Delta_{h}(t)$ : 昇降舵角 $\mathrm{rad}$

$T$ : 推力 $\mathrm{N}$

$m:$ 質量 $\mathrm{kg}$

$I_{y}: y$ 軸まわりの慣性モーメント $\mathrm{kg} \cdot \mathrm{m}^{2}$

$\rho:$ 大気密度 $\mathrm{kg} / \mathrm{m}^{3}$

$S:$ 主翼面積 $\mathrm{m}^{2}$

$\bar{C}:$ 主翼平均空力翼弦長 $\mathrm{m}$

$g:$ 重力加速度 $\mathrm{m} / \mathrm{s}$

$V_{T}$ : 大気速度 $\mathrm{m} / \mathrm{s} \quad V_{T}^{2}=V^{2}+W^{2}$

$A$ : 迎角 $\operatorname{rad} A=\tan ^{-1}(W / V)$

$C_{x}:$ 前後方向無次元化空気力

$C_{z}:$ 上下方向無次元化空気力

$C_{m}: y$ 軸まわりの無次元化モーメント

$C_{m q}: y$ 軸まわりの無次元化係数

$C_{x d h}:$ 前後方向無次元化昇降舵係数

$C_{z d h}$ : 上下方向無次元化昇降舵係数

$C_{m d h}: y$ 軸まわりの無次元化昇降舵係数

また，規範モデルとして，次のような一次線形シス テムを考える。

$y_{M}(t)=a /(s+a) u_{M(t)}$

ここで, $u_{M(t)}$ は, 一定値であり, $a$ は, $a>0$ なる任意 の実数である.

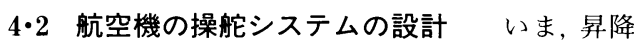
舵角によるピッチ角制御システム(PACS：Pitch Angle Control System)を考える。つまり, 出力方程 式は, 次のように表される.

$$
y(t)=\Theta(t)
$$

この航空機の縌の運動方程式および規範モデルに第 3 章のステップ 1 からステップ 4 までの出力の微分操 作を施すと，次式が得られる.

$$
\begin{array}{r}
\left(s+g_{0}\right)^{2} y(t)=\left[\left(\rho S \bar{C}^{2} / 4 I_{y}\right) V_{T} C_{m q}+2 g_{0}\right] Q(t) \\
\quad+g_{0}^{2} \Theta(t)+\left(\rho S \bar{C} / 2 I_{y}\right) V_{T}^{2}\left(C_{m}+C_{m d h} \Delta_{h}(t)\right)
\end{array}
$$

$$
\left(s+g_{0}\right)^{2} y_{M}(t)=\left(g_{0}-a\right)^{2} y_{M}(t)+a\left(2 g_{0}-a\right) u_{M}(t)
$$


ゆえに, モデル適合制御系のための制御入力は, 次 のようになる。

$$
\begin{aligned}
& \Delta_{h}(t)=\left\{\left(\rho S \bar{C} / 2 I_{y}\right) V_{T}^{2} C_{m d h}\right\}^{-1} \\
& \quad \times\left\{-\left(\rho S \bar{C} / 2 I_{y}\right) V_{T}^{2} C_{m}-g_{0}^{2} \Theta(t)\right. \\
& \quad-\left[\left(\rho S \bar{C}^{2} / 4 I_{y}\right) V_{T} C_{m p}+2 g_{0}\right] Q(t) \\
& \left.\quad+\left(g_{0}-a\right)^{2} y_{M}(t)+a\left(2 g_{0}-a\right) u_{M}(t)\right\}
\end{aligned}
$$

ここで, $D a$ の逆行列は $V_{T} \neq 0$ で常に存在する.

次に, 昇降舵角による上下速度制御システム (VVCS : Vertical Velocity Control System)を考え る.

つまり, 出力方程式は, 次のように表される.

$$
y(t)=W(t)
$$

この航空機の縦の運動方程式および規範モデルに第 3 章のステップ 1 からステップ 4 までの出力の微分操 作を施すと, 次式が得られる.

$$
\begin{gathered}
\left(s+g_{0}\right) y(t)=(\rho S / 2 m) V_{T}^{2}\left(C_{z}+C_{z d h} \Delta_{h}(t)\right) \\
\quad+g \cos \Theta(t)+V(t) Q(t)+g_{0} W(t) \cdots \cdots \cdots \\
\left(s+g_{0}\right) y_{M}(t)=\left(g_{0}-a\right) y_{M}(t)+a u_{M}(t) \cdots \cdots
\end{gathered}
$$

ゆえに, モデル適合制御系のための制御入力は, 次 のようになる。

$$
\begin{aligned}
& \Delta_{h}(t)=\left\{(\rho S / 2 m) V_{T}^{2} C_{z d h}\right\}^{-1}\left\{-(\rho S / 2 m) V_{T}^{2} C_{z}\right. \\
& \quad-g \cos \Theta(t)-V(t) Q(t)-g_{0} W(t) \\
& \left.\quad+\left(g_{0}-a\right) y_{M}(t)+a u_{M}(t)\right\} \quad \cdots \cdots \cdots \cdots \cdots \cdots(23)
\end{aligned}
$$

次に, 昇降舵角による $\mathrm{C}^{*}$ 制御システム $\left(\mathrm{CCS}: \mathrm{C}^{*}\right.$ Control System)を考える. 出力方程式, つまり, $\mathrm{C}^{*}$ 基準は，次のように表される。

$$
\begin{aligned}
& y(t)=-\dot{W} / g+\left(V_{c o}+V_{o}\right) \dot{Q}(t) / g \\
& +\left(I_{p} / g\right) Q(t) \cdots
\end{aligned}
$$

この場合, 出力に入力の直達項があるので, 直ちに 次式が得られる。

$$
\begin{aligned}
y( & t)=-\left\{(\rho S / 2 m) V_{T}^{2}\left(C_{z}+C_{z d h} \Delta_{h}(t)\right)\right. \\
& +g \cos \Theta(t)+V(t) Q(t)\} / g \\
& +\left(V_{c o}+V_{o}\right)\left\{( \rho S \overline { C } / 2 I _ { y } ) V _ { T } ^ { 2 } \left(C_{m}\right.\right. \\
& \left.\left.+C_{m d h} \Delta_{h}(t)\right)+\left(\rho S \bar{C}^{2} / 4 I_{y}\right) V_{T} C_{m q} Q(t)\right\} / g \\
& +\left(I_{p} / g\right) Q(t) \cdots \cdots \cdots \cdots \cdots \cdots \cdots \cdots \cdots \cdots \cdots \cdots \cdots \cdots \cdots \cdots \cdots \cdots \cdots \cdots \cdots \cdots \cdots \cdots
\end{aligned}
$$

ゆえに, モデル適合制御系のための制御入力は, 次 のようになる.

$$
\begin{aligned}
& \Delta_{h}(t)=\left\{\left(V_{c o}+V_{o}\right)\left(\rho S \bar{C} / 2 I_{y}\right) V_{T}^{2} C_{m d h}\right. \\
& \left.\quad-(\rho S / 2 m) V_{T}^{2} C_{z d h}\right\}^{-1}\left\{+(\rho S / 2 m) V_{T}^{2} C_{z}\right. \\
& \quad+g \cos \Theta(t)+V(t) Q(t) \\
& \quad-\left(V_{c o}+V_{o}\right)\left(\rho S \bar{C} / 2 I_{y}\right) V_{T}^{2} C_{m}-\left(V_{c o}\right. \\
& \left.\quad+V_{o}\right)\left(\rho S \bar{C}^{2} / 4 I_{y}\right) V_{T} C_{m q} Q(t)-I_{p} Q(t) \\
& \left.\quad+g y_{M}(t)\right\} \ldots \ldots \ldots \ldots \ldots \ldots \ldots \ldots \ldots \ldots \ldots \ldots \ldots \ldots \ldots \ldots \ldots \ldots \ldots \ldots \ldots \ldots
\end{aligned}
$$

$4 \cdot 3$ 計算機シミュレーション 本節では, 提案 した手法の有効性を検証するために, 計算機シミュレ ーションを実行する.
シミュレーションでは, 線形モデル適合制御入力 (短周期近似された縦の線形運動方程式を基礎として 求めたもの)を用いたときとの結果比較も示す。この 場合の制御入力は，次のようになる.

線形ピッチ角制御システム：

$$
\begin{aligned}
& \Delta_{h}(t)=\left\{\left(\rho S \bar{C} / 2 I_{y}\right) V_{T 0}^{2} C_{m d h}\right\}^{-1} \\
& \quad \times\left\{-\left(\rho S \bar{C} / 2 I_{y}\right) V_{T 0}^{2} C_{m 0}-g_{0}^{2} \Theta(t)\right. \\
& \quad-\left[\left(\rho S \bar{C}^{2} / 4 I_{y}\right) V_{T 0} C_{m q 0}+2 g_{0}\right] Q(t) \\
& \left.\quad+\left(g_{0}-a\right)^{2} y_{M}(t)+a\left(2 g_{0}-a\right) u_{M}(t)\right\}
\end{aligned}
$$

線形上下速度制御システム：

$$
\begin{aligned}
& \Delta_{h}(t)=\left\{(\rho S / 2 m) V_{T 0}^{2} C_{z d h}\right\}^{-1} \\
& \times\left\{-(\rho S / 2 m) V_{T 0}^{2} C_{z 0}-g-g_{0} W(t)\right. \\
& \left.+\left(g_{0}-a\right) y_{M}(t)+a u_{M}(t)\right\}
\end{aligned}
$$

線形 $\mathrm{C}^{*}$ 制御システム :

$$
\begin{aligned}
& \Delta_{h}(t)=\left\{\left(V_{c o}+V_{o}\right)\left(\rho S \bar{C} / 2 I_{y}\right) V_{T 0}^{2} C_{m d h}\right. \\
& \left.\quad-(\rho S / 2 m) V_{T 0}^{2} C_{z d h}\right\}^{-1}\left\{(\rho S / 2 m) V_{T 0}^{2} C_{z 0}\right. \\
& \quad+g-\left(V_{c o}+V_{o}\right)\left(\rho S \bar{C} / 2 I_{y}\right) V_{T 0}^{2} C_{m 0} \\
& -\left(V_{c o}+V_{o}\right)\left(\rho S \bar{C}^{2} / 4 I_{y}\right) V_{T 0} C_{m q 0} Q(t) \\
& \left.\quad-l_{p} Q(t)+g y_{M}(t)\right\} \ldots \ldots \ldots \ldots \ldots \ldots \ldots \ldots \ldots \ldots \ldots \ldots \ldots \ldots \ldots \ldots \ldots
\end{aligned}
$$

ただし， $V_{T 0}, C_{z 0}, C_{m q 0}, C_{m 0}$ は $V(0), W(0)$ に対する 値である.

$$
\begin{array}{lll}
\text { シミュレーション条件は } \\
\text { 前後速度 } & 220 & \mathrm{~m} / \mathrm{s} \\
\text { 上下速度 } & 110 & \mathrm{~m} / \mathrm{s} \\
\text { ピッチ角速度 } & 0 & \mathrm{deg} / \mathrm{s}^{2} \\
\text { ピッチ角 } & 0.09483 & \mathrm{deg} / \mathrm{s}
\end{array}
$$

前後速度：

$$
V_{o}=220 \mathrm{~m} / \mathrm{s}
$$

質量：

$$
m=22695 \mathrm{~kg}
$$

$y$ 軸まわりの慣性モーメント：

$$
I_{y}=427348 \mathrm{~kg} \cdot \mathrm{m}^{2}
$$

大気密度 :

$$
\rho=0.5495 \mathrm{~kg} / \mathrm{m}^{3}
$$

主翼面積 :

$$
S=49.77 \mathrm{~m}^{2}
$$

主翼平均空力翼拡長：

$$
\bar{C}=2.76 \mathrm{~m}
$$

前後方向無次元化空気力：

$$
C_{x}=2.429 A^{2}-0.1959 A-0.03
$$

上下方向無次元化空気力：

$$
C_{z}=-11.16 A^{2}-1.776 A-0.08
$$

$y$ 軸まわりの無次元化モーメント:

$$
C_{m}=-7221 A^{2}-1.083 A+0.063
$$

$y$ 軸まわりの無次元化係数 :

$$
C_{m q}=-25.61 A^{2}+23.09 A-26.04
$$


前後方向無次元化昇降舵係数 :

$C_{x d h}=0.2464 \quad 1 / \mathrm{rad}$

上下方向無次元化昇降舵係数：

$C_{x z h}=0.8480 \quad 1 / \mathrm{rad}$

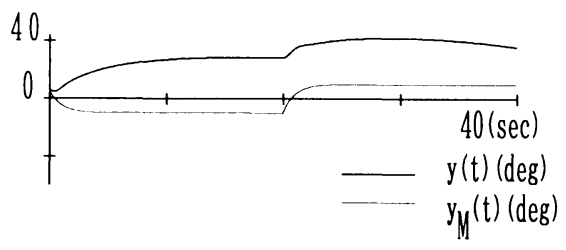

Fig. 1 Responses of linear PACS
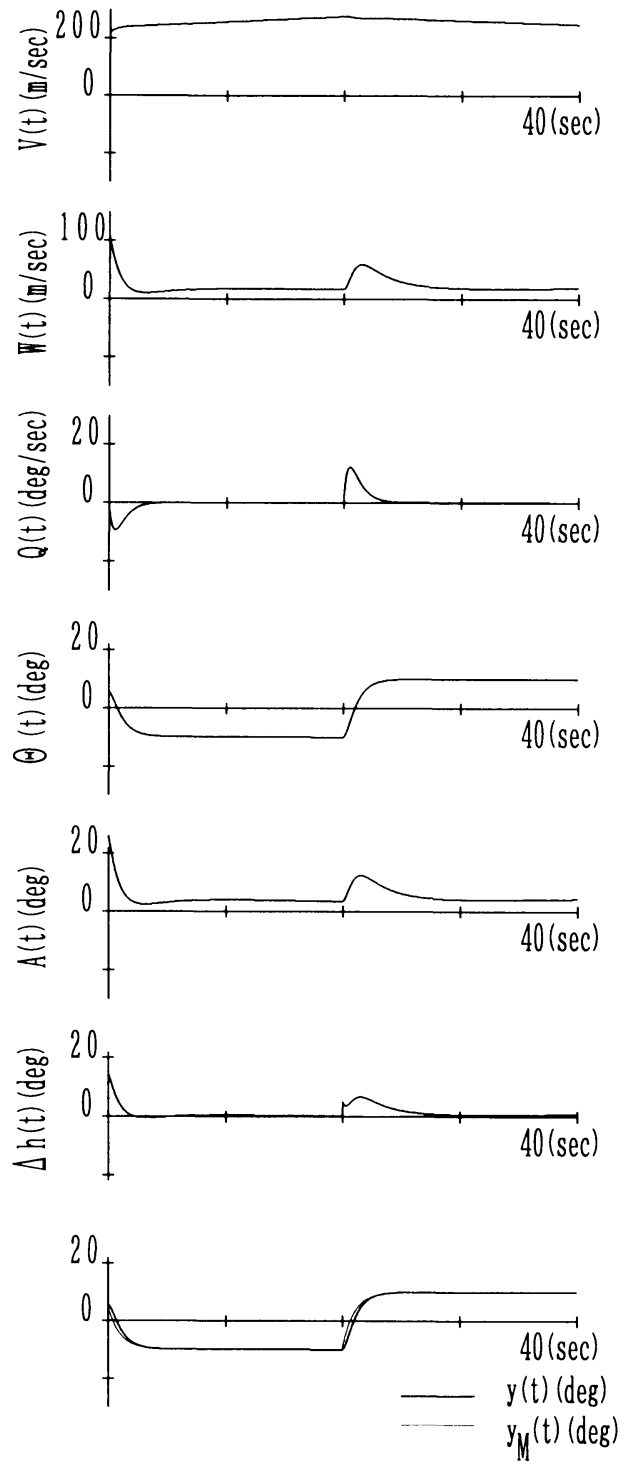

Fig. 2 Responses of nonlinear PACS $y$ 軸まわりの無次元化昇降舵係数 :

$$
\begin{aligned}
& a=1, \quad g_{0}=2 \\
& u_{M}=-10 \mathrm{deg},+10 \mathrm{deg} \text { (ピッチ角制御) } \\
& u_{M}=30 \mathrm{~m} / \mathrm{s}, \quad-10 \mathrm{~m} / \mathrm{s} \text { (上下速度制御) } \\
& u_{M}=1, \quad 0 \text { (C* 制御) }
\end{aligned}
$$

である.なお，計算機シミュレーションとして，次の ような小形高速機の高度 $7600 \mathrm{~m}$ におけるデー夕を用 いる.

$$
C_{m d h}=1.719 \quad 1 / \mathrm{rad}
$$

シミュレーション結果を, 図 1 から 6 に示す.

これらの結果より, 以下のことがわかる.

（1）ピッチ角制御においては，その応答図から線 形モデル適合制御システムでは, 絶えず出力誤差が大 きく残っているのに対して, 非線形システムの場合に は, 過渡状態を除いてシステムがモデルによく追従し ていることがわかる。

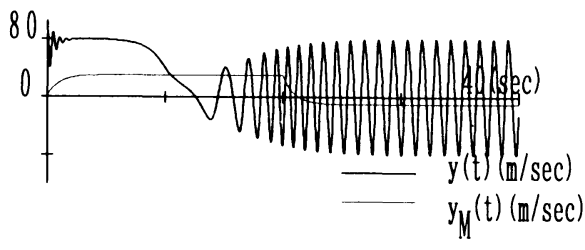

Fig. 3 Responses of linear VVCS

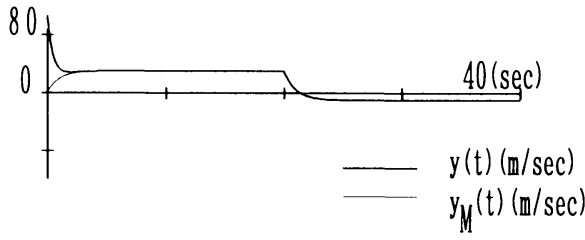

Fig. 4 Responses of nonlinear VVCS

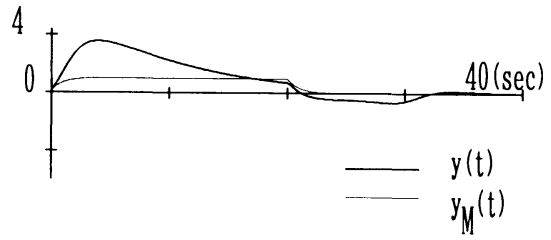

Fig. 5 Responses of linear CCS

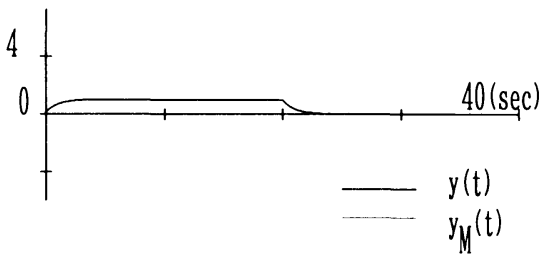

Fig. 6 Responses of nonlinear CCS 
（2）上下速度制御においては, 線形モデル適合制 御システムの応答は振動しながら少しずつ発散してい る.これに対し, 非線形の場合は良好な結果が得られ ている.

（3） C* 制御においては, 線形の場合の出力は, 最 初から発散したため, $W(0)=0$ の場合であるが, 出力 誤差が大きく受け入れ難い応答を示している. 非線形 の場合は, システムの出力がモデルに追従し良好な結 果が得られている.

（4）いずれの場合にも, 提案した非線形モデル適 合制御システムは良好の結果を示しており, 本有効性 が確認できる.

\section{5. あと がき}

本論文では, 非線形モデル適合制御システムの一設 計法を提案し, 航空機の操舵システムへの応用を検討 した.

本方式は, Silvermanの Structure Algorithm を拡 張したHirschornのアルゴリズムを基礎としたもの であり, 出力の微分操作により, 入力信号の出力への 影響度を求めることによって容易に制御則を決定する ことが可能な点に特徵がある. また, この手法は, 結 果として, Wolovichの提案したインタラクタ・マト リックスを出力に左から操作して制御則を求める線形
モデル適合制御方式の拡張になっている。

次に, 提案した制御システムの航空機操舵システム (ピッチ角制御, 上下速度制御, $C^{*}$ 制御システム) へ適 用し, 計算機シミュレーションを実行して, その有効 性を立証した。

今後の課題としては, 本方式の適応非線形システム への拡張である。

\section{文献}

（1） SICE，，自動制御ハンドブック，(1983)，635-645，計測自 動制御学会.

（2）金井喜美雄, フライトコントロール, (1985)，6-14, 椬書店.

（3）加藤寛一郎, 航空機力学入門，(1982)，237-255, 東大出版 会.

(4) Etkin. B., Dynamics of Flight-stability and Control, (1982), 3-18, John Wiley and Sons.

(5) Silverman, L. M. and Moore, B. C., Model Matching by State Feedback and Dynamic Compensation, IEEE AC-17-4 (1972), 491-497.

(6) Hirschorn, R. L., Invertibility of Multivariable Nonlinear Control Systems, IEEE AC-24-6 (1979), 855865.

（7）小菅一弘, 東京工業大学修士論文, (1980)

(8) Wolovich, W. A., Linear Multivariable Systems, (1974), 269-329, Springer-Verlag.

（9）金井喜美雄・内門茂，未知インタラクタを含む CCV 用適 応飛行制御系設計，日本航空宇宙学会誌，34-387 (1986), 211-221. 